DOI 10.37882/2223-2982.2021.05.35

\title{
АРТИКЛЬ И ЕГО РОЛЬ В ВЫРАЖЕНИИ КОНЦЕПТА ОПРЕДЕЛЁННОСТИ-НЕОПРЕДЕЛЁННОСТИ В СОВРЕМЕННОМ АНГЛИЙСКОМ ЯЗЫКЕ
}

\section{THE ARTICLE AND ITS ROLE IN THE EXPRESSION THE CONCEPT OF DEFINITENESS AND INDEFINITENESS IN MODERN ENGLISH}

E. Tymchuk

L. Gamaeva

Summary: The article considers a unique character of English articles that play the key role in the realization of the concept of definiteness and indefiniteness.

It is pointed out that in spite of the universal character of the concept for any egocentric model of human society its linguistic realization is different in form and meaning. The uniqueness of English model in linguistic realization of the concept of definiteness and indefiniteness lies in the fact that English possesses a special system of function words and three formal means of concept expression - the definite article, the indefinite article and the zero article.

The research uses classical methods of linguistic investigation: semantic, lexical-phraseological, typological, comparative and contrastive analysis.

Keywords: concept, definite article, indefinite article, zero article, egocentric model, universal character.

\author{
Тымчук Елена Викторовна \\ Д.филол.н., дочент, ФГБОУ ВО «Кубанский \\ государственный технологический университет» \\ timchuk_elena@mail.ru \\ Гамаева Людмила Анатольевна \\ старший преподаватель, ФГБОУ ВО «Кубанский \\ государственный технологический университет» \\ Igamaeva@yandex.ru
}

Аннотация: (татья рассматривает уникальный характер английских артиклей, играющих ключевую роль в выражении концепта определённости-неопределённости. Отмечается, что, несмотря на универсальный характер данного концепта для любой эгоцентричной модели человеческого общества, его языковая реализация является различной по форме и содержанию. Уникальность английской модели языковой реализации концепта определённости-неопределённости заключается в наличии специальной системы служебных слов и трех формальных способов выражения концепта - определённого артикля, неопределённого артикля и нулевого артикля.

В работе используются классические методы лингвистического исследования: семантический, лексико-фразеологический, типологи-ческий, сопоставительный с элементами сравнительно-исторического.

Ключевые слова: концепт, определённый артикль, неопределённый артикль, нулевой артикль, эгоцентрическая модель, универсальный характер.

современного английского языка из произведений классической английской литературы, отдельные примеры, сопоставимые по семантике и синтактике приведённого для анализа английского материала, иллюстрирующие употребление артиклей в современном немецком и французском языке.

Концепт определенности и неопределенности находит своё выражение в любом языке, поскольку относится к базовым понятиям в любом развитом человеческом социуме. Он появляется на том этапе развития общества, когда отдельная языковая личность осознаёт свою значимость, выделяя себя и свой мир из мира своего рода, и создаёт эгоцентричную картину мира, в которой весь мир вещей физического мысленного плана делится на две важнейшие категории - категорию определенности и категорию неопределенности. Иными словами, это то, что определённо и понятно, потому что это свой мир привычных вещей, и то, что является новым, непонятным, чуждым и даже враждебным.

Такое восприятие жизни и одинаковое видение мира
В качестве материала для исследования были использованы иллюстративный материал словарей и грамматик современного английского языка, образцы
Методологическую основу данной научной работы составляют классические методы лингвистического ский, типологический, сопоставительный с привлечением некоторых фактов диахронического анализа английского языкового материала. 
основывается на единстве физической, психической и социальной природе человека и поэтому в целом не зависит от культурно-исторических условий развития того или иного общества [1, с. 535]. Как базовая сущность концепт определённости и неопределённости находит свое обязательное выражение в любом языке, независимо от его генеалогической и типологической принадлежности.

Вместе с тем универсальность данного концепта не отменяет того разнообразия языковых средств, которые используются в языках разных систем для его выражения. Например, в славянских языках, которые относятся к флективному типу, - это разнообразные лексические и синтаксические средства, в том числе, усилительные частицы (например, русская частица же: он-же), которые остались в этих языках разнородными и не сложились в единую языковую категорию.

В отличие от славянских языков, во всех западноевропейских языках, прежде всего в романских и германских языках, относящихся к языкам аналитического типа, основным средством выражения данного противопоставления является система аналитических форм существительных с определяющими служебными словами - артиклями. При этом во всех этих языках артикли были образованы по одной модели из разных по значению и статусу слов - ослабленного указательного местоимения и числительного со значением один. Эти два служебных слова, которые в русской грамматической традиции были названы членами или артиклями, еще со времени Я. Гримма рассматривались как основные грамматические показатели значения определенности и неопределенности существительного в германских и романских языках [2, с. 14]. По мнению некоторых исследователей, в большинстве этих языков оба артикля противопоставлены их значащему отсутствию, т.е. артиклю 'нулевому'. «Нулевой» артикль при своём возникновении не получил у исследователей однозначную семантическую трактовку. Для одних исследователей нулевой артикль был «значащим отсутствием» положительных артиклей, выражающим обобщённое представление о лице, предмете или явлении. Такое понимание снимало вопрос об определённости или неопределённости рассматриваемого лица, предмета или явления, причём такая форма была омонимична примерам «опущения» артикля [3, с.18]. Для других - это новая степень неопределённости лица, предмета или явления, т.е. такая трактовка, которая логично укладывалась в «семантически расширенное понимание» категории определённости-неопределённости [4, с. 189].

Следует отметить, что несмотря на кажущуюся универсальность систем артиклей в разных западноевропейских языках, их конкретное воплощение уникально и культуроспецифично, ибо реальное языковое воплощение концепта не означает абсолютной эквивалент- ности в его языковой реализации [5, с.18] и оказывается осложненным различными моментами культурологического характера, связанными с историей, культурой и национальным характером данного народа[6, с.124-158].

Так, в силу особенностей своего исторического развития английский язык не сохранил формы рода и падежа существительного. В отличие от английского другие западноевропейские языки, например, немецкий, либо сохранили форму рода и форму падежа, либо, как, например, французский и шведский языки, сохранили только форму рода. В результате, в соответствии с законами синтактики, третий «член» оппозиции артиклей - нулевой артикль - во французском, немецком и шведском языках встречается значительно реже, чем в английском. Это объясняется тем, что употребление положительных артиклей в этих языках связано с выражением грамматических форм имени существительного - форм рода и падежа. Чаще всего нулевой артикль в немецком, французском и шведском языке представляет собой омонимичный нулевому артиклю случай синтаксического или стилистического «опущения» артиклей. Такое опущение подразумевает намеренное неупотребление положительных артиклей в тех позициях, где выражение концепта определённости-неопределённости нивелируется под влиянием различных внутриязыковых и экстралингвистических факторов. К первым относится всё то, что связано с синтактикой языка, т.е. с законами сочетаемости, ко вторым - то, что связано с семантикой и прагматикой языка и основано на экстралингвистических запретах выражаемого языкового содержания, связанного с анализируемым концептом.

Таким образом, языковое выражение концепта определённости-неопределённости через грамматическую категорию артикля является уникальным, несмотря на свою кажущуюся универсальность. Это приводит к соответствующим неудачам в правильном выражении значений определённости - неопределённости, когда английский язык рассматривается сквозь призму других западноевропейских языков и наоборот.

Так, употребление английского определенного артикля на французский манер, например, перед названиями аспектов научной деятельности человека, сразу вызывает в английском языковом сознании на франкоязычное употребление определённого артикля. Этот ассоциативный образ настолько прочно вошёл в сознание английской языковой личности, что может использоваться как маркированная речевая характеристика героя художественного произведения, позволяющая единым речевым штрихом указать на французское происхождение героя художественного произведения. Такой пример часто используют английские писатели для создания эффекта речи иностранца на английском языке. Подобное французское употребление артиклей мы встречаем 
в рассказах Агаты Кристи, где с помощью такого приема создается речевой портрет франкоговорящего героя рассказа - Пуаро.

"Si, si mon ami, it is a pity that you study not the phychology", - говорит Пуаро своему другу, употребляя определенный артикль 'the' перед словом «психология» [7, р. 22], что абсолютно противоречит нормам английского словоупотребления и используется как художественный прием создания образа франкоговорящего героя, плохо владеющего английским языком.

Таким образом, закономерное, на первый взгляд, тождество близкородственных языков оборачивается их полным несходством, потому что в противоположность английскому языку в современном французском, как и в современном немецком языке, артикль употребляется, прежде всего, для выражения рода имени существительного.

Так, например, названия научных и учебных дисциплин употребляются в немецком языке так же, как и в приведённых выше примерах из французского языка, с определенным артиклем: die Mathematik, die Physik, die Medizin. Случаи, когда в немецком или французском языке, как и в английском языке, употреблялся бы нулевой артикль, являются исключениями и обусловлены чисто грамматическими причинами. Продемонстрировать это можно на примере использования названия дисциплины в качестве слов, обозначающих предмет изучения или преподавания: ср. Mathematik (Physik, Medizin) studieren. Именно отличия в употреблении определенного артикля в английском и немецком языках, обусловленные разным восприятием значений определенности и неопределенности имени существительного, можно считать одной из причин возникновения устойчивых ассоциаций в английском национальном сознании при восприятии немцев как людей прямолинейных и пунктуальных, но несколько ограниченных и неумных.

Исследователи немецкого языка традиционно соотносили систему артиклей в данном языке с показателем «известности» и «неизвестности» предмета, обозначаемого существительным, которое логически пересекается с концептом определённости-неопределённости. Такая логическая интерпретация концепта определённостинеопределённости также включает в себя представление о знакомом и незнакомом, впервые встречающемся и имеющем связь с прошлым [8, р.392]. Наиболее полное развитие данное понимание концепта определённостинеопределённости получило в трудах Пола Кристоферсена, так называемая теория «известного-неизвестного» -"familiarity theory" [9, р.49]. Исходя из данного понимания значения артиклей, определенный артикль следует употреблять с существительными, обозначающими предметы, «известные» говорящему и слушающему. И, наоборот, неопределенный артикль следует употреблять с существительными, обозначающими предметы, «неизвестные» как говорящему, так и слушающему.

Данное понимание значений определённости-неопределённости не даёт ответа, как поступать в ситуациях, когда предмет разговора известен говорящему лицу, но неизвестен слушающему лицу (или известен слушающему лицу, но неизвестен говорящему лицу). Кроме того, такой подход исключает существование нулевого артикля, так как его невозможно отнести к какому-то одному из предложенных значений.

Безусловно, деление на известное/неизвестное значение не охватывает все возможные случаи употребления артиклей, поэтому такая трактовка значений определённости-неопределённости, выражаемых артиклями, не даёт реального понимания этого языкового явления в английском языке.

Количественная теория значений определённости-неопределённости рассматривалась на немецком и английском материале [10, с.218-226]. Согласно этой теории, определенный артикль указывает на существительное, обозначающее единственно возможный предмет, о котором говорят в конкретной речевой ситуации. Неопределенный артикль, соответственно, указывает на один предмет из ряда подобных предметов.

Теория, в основе которой лежит количественный принцип определения значения определённости-неопределённости в английском языке, используется Н.Л. Огуречниковой. Лексическое значение английских артиклей определяется как «количественная информация о содержании речевых единиц (слов в речи и синтагм), выделенных при помощи артикля; определенный артикль, указывая на наличие одного варианта содержания у слова или словосочетания в речи, характеризует соответствующий фрагмент текста как однозначный; неопределенный артикль указывает на потенциальную вариантность речевого содержания у слова или словосочетания, - как неоднозначный» [11, с.7]. Существование нулевого артикля в рамках данной теории, как и в классической теории артиклей, объясняется функцией генерализации (обобщения), которую он выполняет.

Концептуальные исследования языка в рамках когнитивного направления в современных исследованиях артиклей значительно расширили и углубили понимание данного языкового феномена. В рамках когнитивных исследований были получены ответы на вопросы о непосредственной связи артиклей с такими грамматическими категориями как род и склонение имен существительных, которые дали возможность показать уникальный характер системы артиклей в английском языке[6, c.124-158 ]. 
В немецком и французском языке род имени существительного определяется по артиклю. Например, анализ рекламы на немецком языке, а также текстов художественной литературы показывает, что употребление слов с определенным артиклем, который ясно указывает на род имени существительного, заключает в себе концептуальное понимание предмета обсуждения, вытекающее из наличия соответствующего рода. Например, das Mảdchen (девочка) - это не особа женского пола, а нечто маленькое и неразумное. Другим примером служит фамильярное das Weib - это не женщина, а вещь, вызывающая отрицательные эмоции и пренебрежение, хотя употребление определенного артикля с существительными среднего рода в рекламе может служить примером формирования положительного восприятия продукта, своего рода гарантией качества продукта (например, das Auto!).

В английском языке то обстоятельство, что английское существительное не изменяется в роде и падеже, послужило основой для формирования особого характера системы артиклей в этом языке. Этот особый характер определяется свободой в выражении концепта определённости - неопределённости, не ограниченной необходимостью выражать морфологические категории рода и падежа существительного.

В отличие от других западноевропейских языков, артикль в английском языке получил возможность выйти за пределы семантики имени существительного. В английском языке он может реализовать свою семантику в полном объеме, даже в условиях "bare word" (нулевого слова) [12, Р.403-579]. Он стал важнейшим элементом высказывания, способным изменять, смещать направленность этого высказывания, создавать и изменять любую концептуальную среду для выражения мыслей [13, р. $335,341]$, определяя её как определённую или неопределённую. Эта особенность английского артикля позволила причислить его к классу концептуальных слов, которые в английской терминологической традиции были названы 'shifters'[14, с.12].

Исчезновение форм рода и падежа значительно усилило позиции нулевого артикля. Он действительно стал значащим. Этот фактор усилил значение определённости и сопутствующее ему значением уникальности в семантике определенного артикля. Определенный артикль приобрел весомую роль в предложении, так как стал обладать определенным семантическим весом не только на уровне семантики слова, но и целого текста.

Разница в значении и весе определенного артикля в языках с артиклями четко осознается теми, кто говорит на этих языках как на своих родных. Показателен в этом отношении пример неудачного английского перевода автобиографической книги Сартра 'Les Mots'. В отличие от спокойного, не претендующего на истину в последней и инстанции названия оригинала, перевод 'Les Mots' как 'The Words' вызвал законное возмущение английской читающей публики, поскольку в английском языковом сознании название 'The Words' не соответствовало вложенному в произведение смыслу и звучало очень претенциозно и даже скандально [15, с.65].

В заключение отметим, что концепт определенности и неопределенности и выражающая его система артиклей в английском, немецком и французском языках представляют, как мы видели, ту часть грамматики именного словосочетания и ту часть грамматики текста исследуемых языков, которая рассматривается в каждом из этих языков как особенно важное. Выражение этого концепта необходимо при интерпретации и категоризации внешнего и внутреннего мира человека и общества, в котором он живёт.

Общее значение и определенное подобие в формальном выражении не означают абсолютной эквивалентности в языковом употреблении. Напротив, каждый язык с помощью своей собственной системы форм кодирует именно те семантические различия, которые в каждом конкретном речевом сообществе считаются особенно важными с точки зрения национального менталитета и особенностей национальной истории и культуры [16, с.7]. Именно единство языкового и внеязыкового (культурного) содержания определяет национальную специфику развития концепта определённости и функционирования систем артиклей в английском языке, делая её уникальной по форме и концептуальному содержанию.

\section{ЛИТЕРАТУРА}

1. БЭС. Языкознание. Под ред. В.Н. Ярцевой. М., 2000.685 с.

2. Москальская 0.И. Развитие артикля в древних германских языках. ИЯВШ, 1948, № 4.56 с.

3. Долгина Е.А. Артиклевые формы имени существительного в когнитивно-грамматической современного английского языка. Автореф. дисс. ...д-ра филол.наук.- М.,2010. -55 c.

4. Тымчук Е.В. Общее и отдельное в артиклевой системе английского языка. Дисс. ....д-ра филол.наук.- М., 2006. - 411 с.

5. Вежбицкая А. Семантические универсалии и описание языков. М: Языки русской культуры. М., 1999, 783 с.

6. Тымчук Е.В. Артикль и межкультурная коммуникация. М.: МАКС Пресс, 2005. - 220 c. ISBN 5-317-01549-9. 
7. Christie, Agatha. Poirot Investigates. - N.Y.: Bantam Books, 1986.

8. Encyclopedia of Language and Linguistics, 2004. $-680 \mathrm{p}$.

9. Christophersen P. The Articles. A Study of their Theory and Use in English. - L.: Oxford Univ. Press, 1939. - 201 p.

10. Пропп В.Я. Проблема артикля в современном немецком // Сборник статей памяти акад. Л.В. Щербы / ред. коллегия: Б.А. Ларин и др. Л. : Изд-во Ленинград. гос. ун-та им. А.А. Жданова, 1951. С. 218-226

11. Огуречникова Н.Л. Системный статус, значение и функции артиклей в английском языке: автореф. дис. ... д-ра филол. наук. СПб., 2008. 53 с.

12. Jespersen, 0. A Modern English Grammar on Historical Principles. - L.: George Allen\&Unwin, 1949.- Part 7. -P.403-579.

13. Epstein, Richard. The definite article, accessibility, and the construction of discourse referents. - Cognitive Linguistics, 12-4, 2002. P. 333-378.

14. Jacobson, Roman. Shifters, verbal categories and the Russian verb. Harvard University, 1957. $14 \mathrm{p}$.

15. Follet, W. Modern American usage. - N.Y., 1966, 436 p.

16. Терминасова С.Г. Язык и межкультурная коммуникация. - Слово, М., 2000. 624 с.

( ) Тымчук Елена Викторовна (timchuk_elena@mail.ru), Гамаева Людмила Анатольевна (lgamaeva@yandex.ru).

Журнал «Современная наука: актуальные проблемы теории и практики»

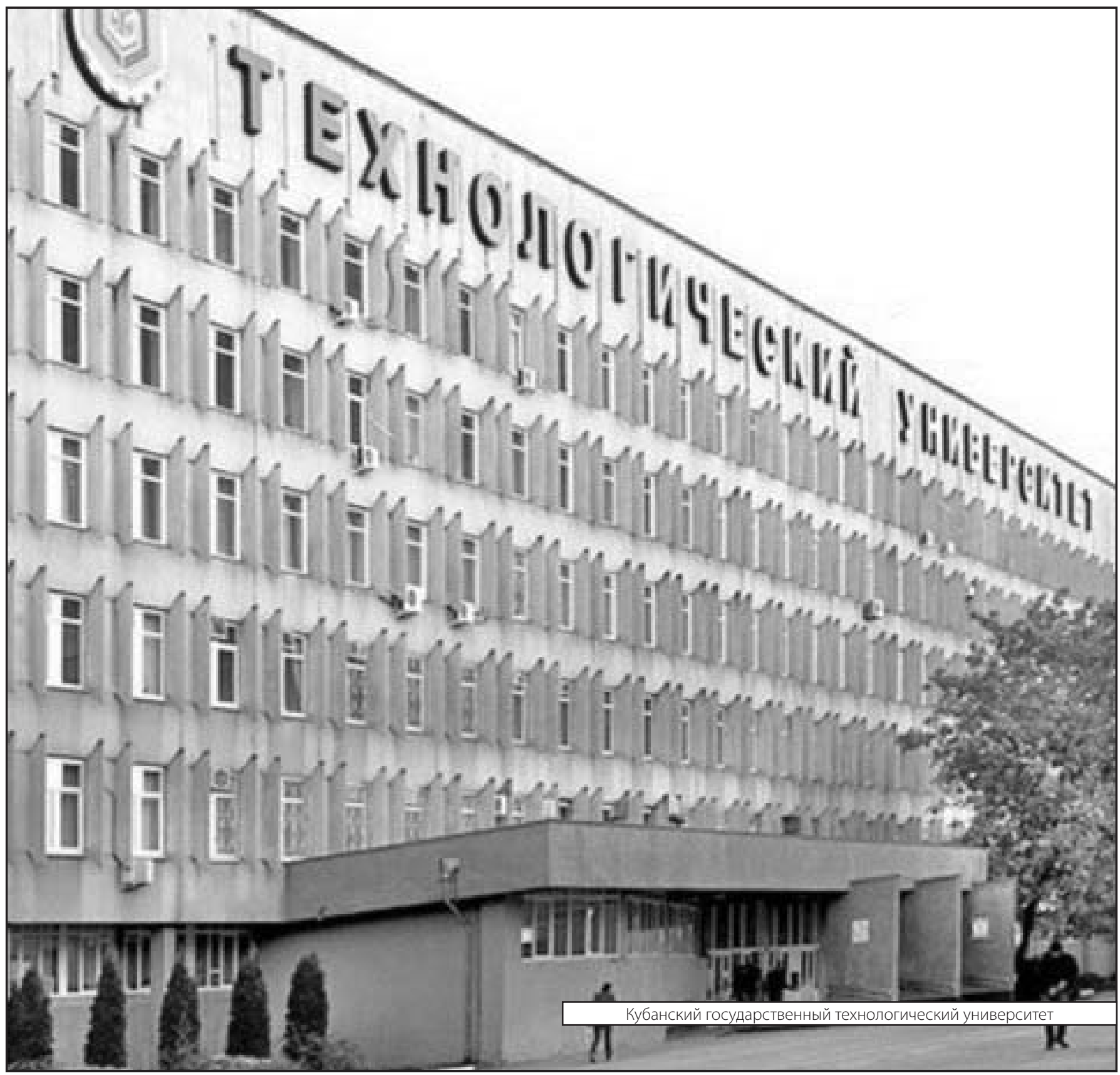

